\title{
Efek Silang Dalam Terhadap Ukuran Tubuh Kerbau Murrah
}

\author{
Muhammad Ary Syaputra*1, Sayed Umar ${ }^{1}$, Asep Gunawan ${ }^{2}$ \\ ${ }^{1}$ Program Studi Ilmu Magister Peternakan, Fakultas Pertanian Universitas Sumatera Utara, Jl. \\ Dr. A. Sofian No, 3 Padang Bulan, Medan 20155 \\ 2 Departemen Ilmu Produksi dan Teknologi Peternakan, Fakultas Peternakan IPB \\ Jl. Agatis Kampus IPB Darmaga, Bogor 16680 \\ *Email korespondensi: syaputra841@gmail.com
}

(Diterima: 09-07-2019; disetujui 27-08-2019)

\begin{abstract}
ABSTRAK
Penelitian ini bertujuan untuk mengetahui pengaruh silang dalam terhadap ukuran tubuh kerbau murrah. Penelitian ini dilaksanakan di BPTU-HPT Siborong-borong dan di peternakan masyarakat Kabupaten Deli Serdang yaitu Desa Tanjung Garbus dan Desa Amplas Tambak Rejo. Penelitian ini menggunakan 41 ekor ternak kerbau murrah terdiri dari 23 ekor betina dan 18 ekor jantan (umur 1-4 bulan) dan data silsilah ternak kerbau murrah. Variabel yang diamati adalah koefisien silang dalam, ukuran populasi efektif, laju silang dalam, dan pengaruh silang dalam terhadap ukuran tubuh kerbau murrah. Hasil penelitian menunjukkan bahwa nilai koefisien silang dalam di BPTU-HPT Siborongborong dan Deli serdang adalah 0,218 dan 0,062. Ukuan populasi efektif kerbau murrah di Sumatera Utara sebesar 61 ekor dengan laju silang dalam per generasi sebesar 0,81\%. Disimpulkan bahwa inbreeding yang terjadi di BPTU-HPT Siborong-borong dan Deli Serdang berpengaruh terhadap ukuran tubuh yaitu nilai rataan tinggi pundak, panjang badan, lingkar dada, lebar dada, dalam dada, tinggi pinggul, lebar pinggul, panjang pinggang, dan lebar pinggang.
\end{abstract}

Kata kunci: kerbau murrah, koefisien silang dalam, laju silang dalam, ukuran populasi efektif, ukuran tubuh

\begin{abstract}
This study was aimed to identify the effect of inbreeding on the body size of murrah buffalo. The research was done in the BPTU-HPT Siborong-borong and the community farm of Deli Serdang Regency (Tanjung Garbus village and Amplas Tambak Rejo village). The sample of murrah buffalo used 41 heads consist of females and males as many as every 23 and 18 heads (age of 1-4 months) and data of murrah buffalo pedigree. The variables measurement were inbreeding coefficient, effective population size, rate of inbreeding and the affect of inbreeding to body size of murrah buffalo. The results showed that the coeficient of the inbreeding coefficient in the BPTU-HPT Siborong-borong and Deli Serdang were 0.218 and 0.062. The effective population size of murrah buffalo in North Sumatra is 61 heads, with the rate of inbreeding per generation were 0.81 percents. It could be concluded that inbreeding that occurred in BPTU-HPT Siborong-borong and Deli Serdang the value of shoulder height, body length, chest circumference, chest width, chest depth, hip height, hip width, waist length, and waist width.
\end{abstract}

Keywords: body size, effective population size, inbreeding coefficient, murrah buffalo, rate of inbreeding

\section{PENDAHULUAN}

Domestikasi kerbau sungai diperkirakan yang pertama berada di India utara sekitar 5000-6000 tahun yang lalu.dan ternak kerbau murrah sampai saat ini selain sumber daging juga merupakan ternak penghasil susu (Wang et al. 2017). Populasi kerbau di Sumatera Utara pada tahun 2017 adalah 108.792 ekor, meningkat menjadi 113.774 ekor pada tahun 
2018, dan untuk ternak kerbau sebagian dipelihara oleh peternak rakyat (DPKH, 2018).

Kerbau memiliki keunggulan dalam mencerna serat kasar yang tinggi, pada kondisi lingkungan ekstrim, dimana ternak ruminansia lain tidak mampu hidup, namun kerbau bisa bertahan hidup dengan baik dan tahan terhadap berbagai macam parasit (Lemcke, 2011). Penurunan mutu genetik dan faktor lain seperti menejemen pemeliharaan yang kurang tepat mengakibatkan penurunan kualitas kerbau Indonesia. Seperti penurunan bobot badan dan ukuran tubuh kerbau disebabkan faktor genetik diantaranya faktor inbreeding atau silang dalam.

Silang dalam adalah perkawinan antara dua individu yang masih mempunyai hubungan kekerabatan. Dua individu dikatakan berkerabat atau mempunyai hubungan keluarga, bila kedua individu tersebut memiliki satu atau lebih tetua bersama (common ancestor) dalam 4 sampai 6 generasi kebelakang (Warwick et al., 1990). Tingkat kekerabatan antara dua individu dalam populasi tergantung dari besarnya populasi. Pengetahuan mengenai ukuran populasi dan laju penurunan populasi suatu rumpun ternak sangat penting untuk mengklasifikasikan status populasi ternak (Subandriyo, 2004). Status populasi dihitung berdasarkan jumlah ternak dewasa dan jumlah populasi efektif

Peningkatan frekuensi homozigot resesif dapat menyebabkan terjadi gen lethal dan penurunan performans atau produksi ternak, perkawinan silang dalam dapat menyebabkan penurunan produksi ternak disebut sebagai tekanan inbreeding. Menurut Roldan and Gomendio (2009) Kejadian inbreeding menyebabkan penurunan kualitas reproduksi dan individu menjadi sensitif terhadap patogen. Penelitian ini dilakukan untuk mengidentifiksi efek silang dalam terhadap ukuran tubuh kerbau murrah.

\section{MATERI DAN METODE}

\section{Bahan dan Alat}

Bahan yang digunakan yaitu ternak kerbau murrah berjumlah 41 ekor yang terdiri dari kerbau betina sebanyak 23 ekor dan kerbau jantan sebanyak 18 ekor (umur 1-4 bulan ). Data silsilah ternak kerbau murrah yang dimiliki oleh BPTU-HPT Siborong-siborong dan Petenakan Masyarakat Kabupaten Deli
Serdang digunakan untuk perhitungan inbreeding. Pengaruh inbreeding terhadap penurunan performa ukuran tubuh juga dilihat dengan mengukur bagian tubuh kerbau diantaranya tinggi pundak, panjang badan, dalam dada, tinggi pinggul, dan panjang pinggul. Pita ukur digunakan untuk mengukur lingkar dada. Caliper digunakan untuk mengukur lebar dada, lebar pinggul dan lebar pinggang. Pengukuran terhadap ukuran-ukuran tubuh dilakukan ketika ternak dalam kondisi berdiri normal dan bobot badan bertumpu pada kedua kakinya dalam kondisi seimbang. Metode pengukuran mengacu berdasarkan Alderson (1999) yang dimodifikasi.

\section{Variabel Penelitian}

Adapun bagian-bagian permukaan tubuh yang diukur sebagai yaitu, Tinggi pundak, diukur dari titik tertinggi diantara bahu (withers) sampai tanah dengan menggunakan tongkat ukur dalam satuan $\mathrm{cm}$. Panjang badan, diukur dari tinggi tertinggi pinggul secara tegak lurus ke tanah dengan menggunakan tongkat ukur dalam satuan $\mathrm{cm}$. Lingkar dada, diukur melingkar di sekeliling rongga dada melalui belakang punuk dengan menggunakan pita ukur dalam satuan $\mathrm{cm}$. Lebar dada, diukur pada jarak antara penonjolan sendi bahu (tuber humerus) kiri dan kanan dengan menggunakan caliper dalam satuan $\mathrm{cm}$. Dalam dada $\left(\mathrm{x}_{5}\right)$, diukur dari titik tertinggi gumba (Os thoracic vertebrae) sampai tulang dada (Os sternum) bagian bawah di belakang kaki depan dengan menggunakan tongkat ukur dalam satuan $\mathrm{cm}$. Tinggi pinggul, diukur dari titik tertinggi pinggul secara tegak lurus ke tanah dengan menggunakan tongkat ukur dalam satuan $\mathrm{cm}$. Lebar pinggul, diukur pada jarak antara tuber coxae kiri dan kanan dengan menggunakan caliper dalam satuan $\mathrm{cm}$. Panjang pinggang, diukur pada jarak antara tuber coxae dan tuber ischii dengan menggunakan caliper dalam satuan $\mathrm{cm}$ dan, Lebar pinggang, diukur jarak antara tuber coxae kiri dan kanan dengan menggunakan caliper dalam satuan $\mathrm{cm}$

\section{Analisa Data}

\section{Perhitungan Koefisien Silang Dalam}

Nilai $\mathrm{F}$ berkisar antara 0 (tidak terjadi inbreeding) sampai 1 (level inbreeding tinggi) dengan rumus sebagai berikut:

$$
f(x)=\frac{1}{2} \sum\left[\left(\frac{1}{2}\right)^{\mathrm{n}+1}\left(1+\mathrm{f}_{\mathrm{a}}\right)\right]
$$


Keterangan:

Fx: koefisien silang dalam ternak x; Fa: koefisien silang dalam tetua bersama; $\mathrm{n}$ : banyaknya tanda panah dari $\mathrm{x}$ ke moyang bersama dan kembali ke $\mathrm{x}$

\section{Perhitungan Ukuran Populasi Efektif (Ne) dan Laju Silang Dalam}

Status populasi dapat ditentukan dengan menghitung jumlah ternak dewasa yang digambarkan dari jumlah betina dewasa dan jumlah populasi efektif. Sedangkan laju silang dalam per generasi dapat dihitung berdasarkan data struktur populasi, yaitu jumlah pejantan dan calon pejantan serta jumlah betina yang dapat dikawinkan dengan rumus yaitu:

$$
\begin{gathered}
N e=\frac{(4 \mathrm{Nm} \mathrm{Nf})}{\mathrm{Nm}+\mathrm{Nf}} \\
\Delta F=\frac{1}{8 N m}+\frac{1}{8 N f}
\end{gathered}
$$

Keterangan:

$\mathrm{Ne}$ : ukuran populasi efektif; $\Delta \mathrm{F}$ : laju silang dalam per generasi; Nm: Jumlah pejantan dan calon pejantan; Nf: Jumlah betina yang dapat dikawinkan.

\section{HASIL DAN PEMBAHASAN}

\section{Nilai koefisien Silang Dalam}

Pengukuranm derajat inbreeeding menggunakan indikator nilai koefisien inbreeding yang dapat dihitung dengan dua cara, yakni dilihat dari sudut individu dan dari sudut populasi. Nilai koefisien inbreeding di Siborong-borong dan Deli Serdang disajikan pada Tabel 1.

Nilai koefisien inbreeding di Siborongborong $(0,218)$ lebih besar dari pada di Deli serdang $(0,062)$. Hal ini menunjukkan bahwa kerbau di Deli serdang memiliki kualitas yang lebih unggul baik secara fenotip maupun genetik. Nilai koefisien inbreeding di Siborong -borong dan Deli Serdang tersebut termasuk kategori sedang. Hal ini disebabkan keterbatasan jumlah pejantan dalam populasi sehingga pergerakan dari setiap individu terbatas. Jumlah ternak suatu populasi sangat mempengaruhi tingkat inbreeding, dimana semakin sedikit ternak maka semakin besar tekanan inbreeding terhadap suatu sifat. Sayed et al. (2012) juga melaporkan bahwa pengaruh tekanan inbreeding terhadap sifat reproduksi menurun $25 \%$ performanya pada populasi kecil dan $8 \%$ pada populasi besar.

\section{Ukuran Populasi Efektif (Ne) dan Laju Silang Dalam}

Suatu populasi yang kecil dapat menyebabkan inbreeding terjadi secara bebas dan sulit dihindari. Peningkatan inbreeding dalam populasi dapat diduga secara kasar berdasarkan jumlah pejantan dan betina yang digunakan di satu populasi. Ukuran populasi efektif dan laju inbreeding di Siborong-borong dan peternakan rakyat di Deli Serdang disajikan pada Tabel 2.

Ukuran populasi efektif (Ne) kerbau murrah masig-masing di Siborong-borong, Tanjung Garbus dan di amplas Tanjung rejo adalah sebesar 22, 25, dan 11 dengan total sebesar 61 dengan laju silang dalam (inbreeding) per generasi sebesar 0,81 persen. Hasil ini menunjukkan bahwa tekanan inbreeding belum terjadi pada populasi kerbau murrah, suatu populasi dapat bertahan apabila laju silang dalam per generasi lebih kecil atau sama dengan satu persen.

\begin{tabular}{|c|c|c|c|c|c|c|}
\hline \multirow{2}{*}{ No. } & \multicolumn{3}{|c|}{ Siborong-borong } & \multicolumn{3}{|c|}{ Deli Serdang } \\
\hline & $\begin{array}{c}\text { Jenis } \\
\text { Kelamin }\end{array}$ & $\begin{array}{c}\text { Nama } \\
\text { Kerbau }\end{array}$ & $\begin{array}{c}\text { Koefisien } \\
\text { Inbreeding }\end{array}$ & $\begin{array}{c}\text { Jenis } \\
\text { Kelamin }\end{array}$ & $\begin{array}{l}\text { Nama } \\
\text { Kerbau }\end{array}$ & $\begin{array}{c}\text { Koefisien } \\
\text { Inbreeding }\end{array}$ \\
\hline 1. & Jantan & S.016 & 0,25 & Betina & Bolli & 0,0625 \\
\hline 2. & Betina & S.018 & 0,25 & & & \\
\hline 3. & Betina & S.038 & 0,125 & & & \\
\hline 4. & Betina & S.040 & 0,25 & & & \\
\hline \multicolumn{3}{|c|}{ Rata-rata } & 0,218 & & & \\
\hline
\end{tabular}

Tabel. 1. Nilai koefisien inbreeding kerbau murrah 
Tabel 2. Ukuran populasi efektif (Ne) dan laju silang dalam per generasi dari kerbau murrah

\begin{tabular}{|c|c|c|c|c|c|}
\hline \multirow[b]{2}{*}{ No. } & \multirow[b]{2}{*}{ Peubah } & \multicolumn{3}{|c|}{ Sumatera Utara } & \multirow[b]{2}{*}{ Total } \\
\hline & & $\begin{array}{l}\text { Siborong- } \\
\text { borong }\end{array}$ & $\begin{array}{l}\text { Tanjung } \\
\text { Garbus }\end{array}$ & $\underset{\text { Rejo }}{\text { Amplas T. }}$ & \\
\hline 1. & $\begin{array}{l}\text { Kerbau jantan dewasa (Number of breed } \\
\text { male, } \mathrm{Nm} \text { ). (ekor). }\end{array}$ & 8 & 7 & 3 & 18 \\
\hline 2. & $\begin{array}{l}\text { Kerbau betina dewasa (Number of breed } \\
\text { female, Nf) (ekor) }\end{array}$ & 17 & 68 & 21 & 106 \\
\hline 3. & Jumlah populasi efektif (Ne) (ekor) & 22 & 25 & 11 & 61 \\
\hline 4. & Laju inbreeding (\%) & 2,29 & 1,96 & 4,75 & 0,81 \\
\hline
\end{tabular}

Ukuran populasi efektif (Ne) kerbau murrah masig-masing di Siborong-borong, Tanjung Garbus dan di amplas Tanjung rejo adalah sebesar 22, 25, dan 11 dengan total sebesar 61 dengan laju silang dalam (inbreeding) per generasi sebesar 0.81 persen. Hasil ini menunjukkan bahwa tekanan inbreeding belum terjadi pada populasi kerbau murrah, suatu populasi dapat bertahan apabila laju silang dalam per generasi lebih kecil atau sama dengan satu persen. Sementara itu Praharani et al. (2009) menyatakan bahwa kenaikan $1 \%$ dari tingkat inbreeding pergenerasi akan menurunkan produksi dan menyebabkan penurunan sifat performa pada ternak. Namun, dalam jangka panjang kecenderungan peningkatan silang dalam dapat saja terjadi jika populasi tetap dalam keadaan terisolir (tertutup) kemudian diikuti oleh sistem perkawinan yang tidak terkontrol.

\section{Pengaruh inbreeding terhadap ukuran tubuh}

Produktivitas kerbau murrah diamati untuk melihat pengaruh tekanan inbreeding. Perbandingan antara ukuran tubuh kerbau murrah yang tidak inbreeding dan inbreeding disajikan pada Tabel. 3

Tabel 3. Ukuran tubuh pedet kerbau murrah

\begin{tabular}{|c|c|c|c|c|c|c|}
\hline \multirow{3}{*}{ No. } & \multirow{3}{*}{ Ukuran tubuh } & \multicolumn{5}{|c|}{ Sumatera Utara } \\
\hline & & \multicolumn{2}{|c|}{ Siborong-borong } & \multicolumn{2}{|c|}{ Tanjung Garbus } & \multirow{2}{*}{$\begin{array}{l}\text { Amplas T.Rejo } \\
\text { Tidak inbreed } \pm \text { SD }\end{array}$} \\
\hline & & Tidak inbreed \pm SD & Inbreed $\pm \mathrm{SD}$ & Tidak inbreed $\pm S D$ & Inbreed & \\
\hline 1. & Tinggi Pundak & $69,81 \pm 4,1$ & $63 \pm 1,4$ & $70,05 \pm 7,6$ & 60 & $68,77 \pm 4,4$ \\
\hline 2. & $\begin{array}{l}\text { Panjang } \\
\text { Badan }\end{array}$ & $55,54 \pm 5,5$ & $48 \pm 3,1$ & $56,94 \pm 3,9$ & 50 & $57,77 \pm 2,9$ \\
\hline 3. & Lingkar Dada & $67,72 \pm 11,3$ & $65,5 \pm 1,2$ & $64,72 \pm 8,2$ & 50 & $64,77 \pm 3,0$ \\
\hline 4. & Lebar Dada & $21,45 \pm 4,1$ & $17,5 \pm 1,2$ & $22,44 \pm 4,0$ & 21 & $22,22 \pm 2,7$ \\
\hline 5. & Dalam Dada & $33,45 \pm 4,4$ & $31,5 \pm 1,7$ & $32,88 \pm 4,0$ & 29 & $28,88 \pm 2,9$ \\
\hline 6. & $\begin{array}{l}\text { Tinggi } \\
\text { Pimggul }\end{array}$ & $67,45 \pm 3,2$ & $66 \pm 1,4$ & $65,94 \pm 7,4$ & 60 & $67,55 \pm 3,6$ \\
\hline 7. & Lebar Pinggul & $22,45 \pm 3,2$ & $18,5 \pm 1,2$ & $22,05 \pm 2,5$ & 21 & $20,22 \pm 2,1$ \\
\hline 8. & $\begin{array}{l}\text { Panjang } \\
\text { Pinggang }\end{array}$ & $18,18 \pm 3,3$ & $15,5 \pm 1,7$ & $17,27 \pm 2,4$ & 16 & $17,11 \pm 1,4$ \\
\hline 9. & $\begin{array}{l}\text { Lebar } \\
\text { Pinggang }\end{array}$ & $18,54 \pm 3,3$ & $14,5 \pm 1,0$ & $22,72 \pm 2,1$ & 19 & $19,44 \pm 1,2$ \\
\hline
\end{tabular}


Secara umum ukuran tubuh kerbau murrah yang tidak inbreeding dibandingkan dengan kerbau murrah yang inbreeding memiliki ukuran tubuh yang relatif lebih besar baik di BPTU-HPT Siborong-borong maupun di kabupaten Deli Serdang (Tabel 3). Salah satu dampak yang disebabkan oleh inbreeding diantaranya menurunkan performas ternak pada generasi berikutnya, hal ini sesuain Neaves et al. (2015) yang menyatakan bahwa pengaruh peningkatan derajat inbreeding terhadap penurunan performans dari berbagai penelitian dari jenis ternak yang berbeda. Sebanyak 81,9\% menyebutkan pengaruh tekanan inbreeding terhadap penurunan daya hidup, 52\% tentang pengaruh negatif terhadap ukuran tubuh, $12,5 \%$ dampak terhadap ketahanan penyakit patogen, parasit, cekaman (stres), dan kegagalan kebuntingan.

Secara umum inbreeding yang terjadi tidak berpengaruh terhadap ukuran tubuh kerbau murrah. Rata-rata tinggi pundak ternak di Siborong-siborong yang tidak inbreeding sebesar 69,81 dan yang inbreeding sebesar 63, ini menunjukan bahwa ukuran tubuh ternak kerbau tidak jauh beberda, hal ini disebabkan karena jumlah populasi pejantan yang terbatas di wilayah tersebut dan umur ternak yang diukur terlalu muda, hal yang sama terjadi diwilayah kabupaten Deli Serdang.

Pada umumnya, tekanan inbreeding akan memberikan pengaruh buruk terhadap sifat yang berkaitan dengan daya ketahanan hidup ternak, fertilitas dan kesehatan ternak (Paige, 2010). Inbreding pada ternak juga bisa mengakibatkan menurunnya kelangsungan hidup yang sangat berhubungan dengan kinerja reproduksi dan mortalitasnya dibandingkan dengan ternak yang tidak inbreeding. Gullstrand (2015) juga menjelaskan tingginya tekanan inbreeding akan mempermuda ternak terserang penyakit yang bisa menyebabkan tingginya kematian pada embryo, neo-natal akibat gen resesif ternak yang memiliki efek negatif.

\section{KESIMPULAN}

Nilai koefisien inbreeding tertinggi di BPTU-HPT Siborong-borong sebesar 0,25, sedangkan yang terendah juga di BPTU Siborong-siborong sebesar 0,125. Jumlah individu yang inbreeding ditemukan sebanyak 26,66\% di BPTU-HPT Siborong-borong dan $5,2 \%$ di desa Tanjung Garbus, sedangkan di desa Amplas Tambak Rejo tidak ditemukan ternak yang inbreeding. Inbreeding yang terjadi tidak berpengaruh terhadap ukuran tubuh kerbau murrah.

\section{UCAPA TERIMAKASIH}

Ucapan terima kasih disampaikan kepada BPTU-HPT Siborong-borong dan peternakan masyarakat kerbau murrah di Kabupaten Deli Serdang atas bantuan untuk lokasi penelitian.

\section{DAFTAR PUSTAKA}

Alderson G.L.H. 1999. The development of a system of linear measurements to provide an assessment of type and function of beef cattle. Animal Genetic Resources Information (AGRI) 25:4555.

[DPKH] Direktorat Jenderal Peternakan dan Kesehatan Hewan 2018. Statistik Peternakan. Direktorat Jenderal Peternakan dan Kesehatan Hewan. Kementerian Peternakan, RI. Jakarta.

Gullstrand, P. 2015. Control of inbreeding in dairy cattle in the genomic era. Bachelor Thesis. Swedish University of Agricultural Sciences. Uppsala. Swedia.

Warwick, E.J., J.M. Astuti, \& W. Hardjosubroto. 1990. Pemuliaan Ternak. Gadjah Mada University Press. Yogyakarta.

Lemcke B. 2011. Is there a major role for buffalo in Indonesia's beef self sufficiency program by 2014?. Prosiding Seminar dan Lokakarya Nasional Usaha Ternak Kerbau: Percepatan Perbibitan dan Pengembangan Kerbau melalui Kearifan Lokal dan Inovasi Teknologi untuk Mensukseskan Swasembada Daging Kerbau dan Sapi serta Peningkatan Kesejahteraan Masyarakat Peternakan. Lebak, 2-4 November 2010. Puslitbangnak. Bogor. Hlm. 1-6.

Neaves, L.E., J. Eales, W. Raj, P.M. Hollingsworth, B. Terry, \& A.S. Pullin. 2015. The fitness consequences of inbreeding in natural populations and their implications for species conservation-A systematic map. Environmental Evidence 4:5 
Paige, K.N. 2010. The functional genomics of inbreeding depression: A new approach to an old problem. Bioscience 60:267277.

Praharani, L., E. Juarni, \& I.G.M. Budiarsana. 2009. Parameter indikator inbreeding rate pada populasi ternak kerbau di Kabupaten Lebak Provinsi Banten. Makalah pada Seminar dan Lokakarya Nasional Kerbau Peningkatan Produktivitas Kerbau Melalui Aplikasi Teknologi Reproduksi dalam Rangka Meningkatkan Kesejahteraan Peternak. Brebes, 11-13 November 2009. Puslitbangnak. Bogor. Hlm 93-99.

Roldan, E.R.S. \& M. Gomendio. 2009. Sperm and conservation. p. 539-564. In Birkhead, T., Rt. Roush, D.J. Hosken, and S. Pitnick (eds.) Biology of Sperm: An Evolutionary Perspective. UK Academic Press. London.

Sayed, A.L., A.M. Shahinez, M. Alsayed, \& A.B. Shiddiq. 2012. Inbreeding coefficient in simulated open nucleus breeding scheme in Egyptian buffalo. Egypt J Anim Prod. 49:1-8.

Subandriyo. 2004. Pengelolaan data plasma nutfah ternak. Buletin Plasma Nutfah 10 (2):90-100.

Wang, N. Chen, M.R. Capodiferro, T. Zhang, H. Lancion, H. Zhang, Y. Miao, V. Chanthakhoun, M. Wanapat, M. Yindee, Y. Zhang, H. Lu, L. Caporali, R. Dang, Y. Huang, X. Lan, M. Plath, H. Chen, J. A. Lenstra, A. Achilli, \& C. Lei. 2017. Whole mitogenomes reveal the history of swamp buffalo: initially shape by glacial periods and eventually modeled by domestication. Sientific Reports 7:4708. 